Rev.Pemo - Revista do PEMO

\title{
Políticas Públicas, Educação para os Direitos Humanos e Diversidade Sexual
}

\author{
Thiago Luiz Sartori \\ Universidade Anhanguera - UniABC, Santo André, SP, Brasil
}

\begin{abstract}
Resumo
O objetivo deste estudo foi analisar as Políticas Públicas e a educação para os direitos humanos e diversidade sexual. Diante dos objetivos expostos, perguntase: qual o papel das Políticas Públicas no sentido de assegurar o acesso e permanência de lésbicas, gays, bissexuais, travestis e transexuais no campo da educação? A metodologia foi a revisão bibliográfica por meio da coleta de informações em livros, revistas científicas, artigos científicos teses e dissertações divulgadas entre 2011 e 2018. Os Estados também devem realizar estudos coletar dados estatísticos sobre educação, desagregados por orientação sexual e identidade de gênero, para informar a política. Finalmente, os Estados devem desenvolver programas de educação sexual que forneçam aos alunos informações abrangentes, precisas e adequadas à idade sobre sexualidade e diversas identidades de gênero.
\end{abstract}

Palavras-chave: Direitos Humanos. Diversidade Sexual. Educação. Políticas Públicas.

\section{Public Policies, Education for Human Rights and Sexual Diversity}

\begin{abstract}
The aim of this study was to analyze Public Policies and education for human rights and sexual diversity. Given the above objectives, the question is: what is the role of Public Policies in ensuring the access and permanence of lesbians, gays, bisexuals, transvestites and transsexuals in the field of education? The methodology was the literature review through the collection of information in books, scientific journals, scientific articles, theses and dissertations published between 2011 and 2018. States must also carry out studies to collect statistical data on education, disaggregated by sexual orientation and gender identity, to inform policy Finally, States should develop sex education programs that provide students with comprehensive, accurate, and age-appropriate information about sexuality and diverse gender identities.
\end{abstract}

Keywords: Human Rights. Sexual Diversity. Education. Public policy. 


\section{PRÁTICAS EDUCATIVAS, MEMÓRIAS E ORALIDADES}

Rev.Pemo - Revista do PEMO

\section{Introdução}

A aprendizagem ao longo da vida "poderia ser alcançada através da educação continuada do público em geral e de prestadores de serviços sociais e de saúde em relação a questões de gênero e sexualidade, juntamente com programas integrados e direcionados para indivíduos e comunidades LGBT (por exemplo, recursos de emprego, como treinamento de habilidades para pessoas trans). Para uma abordagem abrangente, isso precisaria ser realizado tanto formal quanto informalmente em todos os níveis do sistema educacional e em todas as ações de promoção da saúde pública.

O objetivo deste estudo foi analisar o papel das Políticas Públicas no sentido de assegurar o acesso e permanência de lésbicas, gays, bissexuais, travestis e transexuais no campo da educação.

Os objetivos específicos foram: investigar os aspectos relacionados as políticas públicas de educação e aos direitos humanos na diversidade sexual, identificar as vertentes da sexualidade e sua temática no campo da educação e diversidade e, analisar de acordo com os dispositivos da lei de direitos humanos que asseguram a educação e direito a diversidade sexual.

Diante dos objetivos expostos, pergunta-se: qual o papel das Políticas Públicas no sentido de assegurar o acesso e permanência de lésbicas, gays, bissexuais, travestis e transexuais no campo da educação?

Pessoas LGBT cruzam todas as linhas socioeconômicas, étnico-raciais, de idade, gênero, (deficiência), religiosas, localização geográfica, educação e status de relacionamento. Consequentemente, para muitos nessas comunidades, sua existência é composta de múltiplas identidades sociais que se cruzam, especialmente na relação da diversidade sexual e direito à educação.

Acredita-se firmemente que todos têm o direito de realizar seu potencial e de ter a oportunidade de viver sem pobreza em um mundo seguro e mais justo. Sexualidade e identidade de gênero são aspectos positivos, parte central, de ser humano e experimentar bem-estar e realização. E ainda, quando a diversidade de sexualidade e identidade de 


\section{PRÁTICAS EDUCATIVAS, MEMÓRIAS E ORALIDADES}

Rev.Pemo - Revista do PEMO

gênero se torna invisível, ou se torna a base da discriminação, os direitos, as decisões sobre corpos, sexualidades, identidades e relações consensuais íntimas de sua própria escolha são violadas.

Além disso, a pobreza e as desigualdades de gênero podem ser agravadas, e as intervenções de desenvolvimento podem ser inadequadas ou não atingirem as pessoas LGBTI de uma vez, resultando na marginalização múltipla de indivíduos LGBTI. A pobreza é multidimensional e inclui renda e bens insuficientes e falta de acesso a serviços básicos e oportunidades. Mas a pobreza também está profundamente enraizada na desigualdade e pode ser agravada pelo abuso de poder, violência humana, opressão e discriminação. A sexualidade pode contribuir para a forma como as pessoas vivenciam a pobreza e, em muitos casos, resulta em uma pobreza extrema - com base em seu status, direitos legais e acesso a recursos na sociedade.

As questões relacionadas à sexualidade são amplas e abrangem uma diversidade de elementos, desde orientação sexual, saúde e direitos sexuais reprodutivos e prazer sexual.

De acordo com Gil (2010) metodologia de pesquisa bibliográfica compõe-se, basicamente de informações obtidas por meio de procedimentos realizados pelo pesquisador de acordo com a temática do assunto e por meio de dados coletados cientificamente que podem envolver livros, artigos e outras fontes.

Esta pesquisa foi realizada por meio de revisão bibliográfica a partir da coleta de materiais em livros, revistas científicas, artigos científicos teses e dissertações divulgadas entre 2011 e 2018.

\section{Resultados e Discussão}

Historicamente, um padrão comum de promulgação de políticas de não discriminação é a inclusão de proteção para orientação sexual, com a adição posterior de identidade de gênero e proteção de expressão à medida que a educação, ativismo e conscientização sobre questões transgênero crescem (FACCHINI, 2005). 


\section{PRÁTICAS EDUCATIVAS, MEMÓRIAS E ORALIDADES}

Rev.Pemo - Revista do PEMO

Existem várias áreas-chave de mudança proativa que discutirei: legislativa, local de trabalho e ensino superior. As iniciativas legislativas para proteger GI\&E ultrapassaram os avanços na educação em 20 anos e nos negócios em quase 30 anos. A maioria das iniciativas positivas para transgêneros em legislação, negócios e educação estagnaram durante grande parte das décadas de 1970 e 1980, até que o ativismo transgênero encontrou uma nova voz e propósito nas décadas de 1990 e 2000 (LIRA, 2009, p.54).

Simultaneamente ao desenvolvimento de centros de recursos LGBT, a inclusão da orientação sexual nas políticas de não discriminação em faculdades e universidades ocorreu em sua maior parte entre o início dos anos 1970 e meados dos anos 1990; mais de 500 faculdades e universidades adicionaram orientação sexual às suas políticas de não discriminação durante aquele período no Brasil (VIANNA, 2011).

A diversidade é geralmente entendida como abrangendo raça, etnia, classe, gênero, sexualidade, idade e crenças políticas e religiosas. E enquanto no passado ele se concentrou no fortalecimento da tolerância intercultural, novas ideias sobre diversidade e inclusão se desenvolveram, mudando o foco para enriquecer o aprendizado e a experiência humana, a chamada "unidade na diversidade". (ROSSI, 2010).

De acordo com Vianna (2012) a gentes associados, como formuladores de políticas, financiadores e instituições de ensino superior, além de associações profissionais que treinam profissionais de saúde e serviço social, também precisam contribuir para esse processo. Um envolvimento e compromisso com o processo de abordar essas preocupações por parte desses agentes contribuiria para uma prática transformadora na qual a prestação de serviços se tornaria mais inclusiva, acessível, sensível e equitativa em relação ao gênero e sexualmente diversa com uma saúde e bemestar positivos resultado.

A presença da diversidade na sociedade atual é clara e extremamente desafiadora, porque as diferenças socioculturais, econômicas, políticas, sexuais ou físicas podem melhorar significativamente a aprendizagem, o compartilhamento e 0 enriquecimento dos indivíduos. Portanto, a universidade é justamente um dos espaços onde a diversidade pode ser observada com o predomínio da pluralidade de gênero e das identidades sexuais (OLIVEIRA, 2010)

Rev.Pemo, Fortaleza, v. 3, n. 3, e335484, 2021

DOI: https://doi.org/10.47149/pemo.v3i3.5484

https://revistas.uece.br/index.php/revpemo

ISSN: 2675-519X

(c) (i) Esta obra está licenciada com uma Licença Creative Commons

Atribuição 4.0 Internacional. 


\section{PRÁTICAS EDUCATIVAS, MEMÓRIAS E ORALIDADES}

Rev.Pemo - Revista do PEMO

No entanto, restritas por paredes e normas, essas diversidades são frequentemente forçadas a obedecer a padrões sociais arbitrários. Dessa forma, eles ficam impedidos de expressar suas diferenças de forma segura e democrática, resultando em exclusões e segregações (VIANNA, 2011).

Nesse contexto, de acordo com Vianna (2012), a diversidade sexual envolve multiplicidade de expressões da sexualidade e experiências de gênero que compõem o ser humano, incluindo identidades sexuais (heterossexual, homossexual e bissexual) e identidades de gênero, entre as quais se destacam travestis e transexuais.

Observa que a heteronormatividade adota a heterossexualidade como norma socialmente reconhecida. Esse uso obrigatório, geralmente exclui a heterossexualidade como parte do termo de diversidade sexual; pois o que é considerado normal não seria nomeado (VENTURI, BOKANI, 2011).

A discriminação e a segregação ameaçam o papel inclusivo e democrático das escolas. Além disso, esses comportamentos promovem a intolerância à diversidade, causando práticas homofóbicas que vão desde agressões verbais a lesões corporais graves (VIANNA, 2012).

Os jovens LGBTQ + enfrentam níveis mais elevados de estresse, rejeição e bullying do que seus pares heterossexuais. Altos níveis de estresse infantil podem afetar problemas de saúde mental, emocional e física ao longo da vida, além do desempenho acadêmico. Este problema é agravado para os jovens que também vivenciam outras experiências adversas na infância (como traumas físicos, pobreza e racismo sistêmico. Taxas desproporcionalmente altas de jovens LGBTQ + contemplam e cometem suicídio em comparação com seus pares heterossexuais. Claramente, fornece apoio a essa população vulnerável deve ser uma prioridade (ROSSI, 2010).

Estudos demonstraram que, em comparação com seus pares heterossexuais, os jovens LGBTQ + relatam taxas muito mais altas de depressão, ansiedade, uso de álcool e drogas e baixa autoestima. Enquanto muitos alunos lésbicas, gays, bissexuais, transgêneros e queer (LGBTQ) são capazes de navegar com resiliência em sua educação escolar pública, muitos outros vivenciam climas escolares difíceis e resultados 


\section{PRÁTICAS EDUCATIVAS, MEMÓRIAS E ORALIDADES}

Rev.Pemo - Revista do PEMO

educacionais e de saúde negativos. O assédio e a intimidação de alunos LGBTQ em ambientes escolares têm sido associados a vários resultados psicológicos e acadêmicos negativos para alunos com orientação sexual e / ou identidade de gênero. A preparação de candidatos a professores (TCs) para responder de forma eficaz ao assédio e intimidação de alunos e para criar um currículo inclusivo tem sido recomendada para melhorar os resultados para os alunos (AZEVEDO, 1997).

Por outro lado, a educação na diversidade, "é um meio fundamental para desenvolver a compreensão mútua, o respeito e a tolerância, que são os fundamentos do pluralismo, da convivência e da democracia". Entretanto, muitos/as alunos/as experimentam dificuldades de aprendizagem e de participação, porque as escolas continuam dando respostas homogêneas para as diversas situações e necessidades dos (as) mesmos (as), num contexto que é heterogêneo (MICHALISZYM, 2011, p.10).

De acordo com Fonseca (2011, p.42):

[...] os cursos de formação docente mantem uma estrutura curricular de caráter disciplinar, gradeada e fechada à introdução dessas e de outras questões tão caras aos movimentos sociais e tão presente em nossa vida cotidiana. $O$ caráter conservador dos currículos acaba por expulsar qualquer discussão que pontue a diversidade étnico - racial na formação do(a) educador.

Quando se trata de educação, a "unidade na diversidade" na sala de aula não parece mais uma ideia exagerada para qualquer professor de mente global. Isso pode ser conseguido com a tecnologia que conecta os alunos com conhecimentos e culturas estrangeiras ou com um corpo discente internacional para tornar o ambiente de aprendizado multicultural e diversificado.

O conceito de minorias sexuais e de gênero inclui uma diversidade considerável, bem como uma multiplicidade de identidades e comportamentos. Por exemplo, uma mulher transgênero pode ser heterossexual, homossexual, bissexual ou assexuada. Além disso, as minorias sexuais e de gênero têm, simultaneamente, muitas outras identidades pessoais e sociais.

[...] identidades: como mulheres ou homens ou um gênero não binário, elites ou classe trabalhadora, pessoas com deficiência, migrantes, minorias étnicas ou linguísticas, povos indígenas e assim por diante. A interseção dessas identidades pessoais e sociais pode exacerbar ou mitigar a marginalização, assim como a

Rev.Pemo, Fortaleza, v. 3, n. 3, e335484, 2021

DOI: https://doi.org/10.47149/pemo.v3i3.5484

https://revistas.uece.br/index.php/revpemo

ISSN: 2675-519X

(c) (i) Esta obra está licenciada com uma Licença Creative Commons

Atribuição 4.0 Internacional. 


\title{
PRÁTICAS EDUCATIVAS, MEMÓRIAS E ORALIDADES
}

Rev.Pemo - Revista do PEMO

\begin{abstract}
relação (ou a falta dela) entre os avanços sociais relevantes. Neste artigo, pessoas, políticas e ações que são hostis ou discriminatórias contra as minorias sexuais e de gênero são referidas como "homo / transfóbicas", embora reconhecendo a limitação dessa palavra. É importante observar que a exclusão e a discriminação contra as minorias sexuais e de gênero também podem afetar diretamente as pessoas que não se consideram tais minorias; meninos e meninas masculinos são frequentemente vítimas de bullying na escola como resultado de tal discriminação, embora possam se tornar adultos heterossexuais e de gênero típico. Discriminação contra sexo e gênero (FERRARI, 2004, p.23).
\end{abstract}

As minorias também têm impactos claros em suas famílias, como quando filhos de gays ou lésbicas são excluídos da escola ou quando famílias inteiras sofrem devido à presença de um único membro da família que é visto como parte de uma minoria sexual ou de gênero (OLIVEIRA, 2010).

Rossi (2010) afirma eloquentemente que "os gêneros que nos são atribuídos na fechadura do nascimento nós em um curso através do qual se espera que nos tornemos inteiros, completos, criativos, amorosos pessoas - mas apenas como homens ou mulheres"

As escolas servem como um dos ambientes institucionais significativos em que os alunos vêm para compreender seu próprio gênero e interagir com identidades de gênero que podem diferir das suas próprias identidades.

"Um grupo que é largamente deixado de fora das discussões sobre educação consiste em estudantes transexuais e aqueles que transgridem as normas sociais de gênero"( MICHALISZYN, 2011, p. 419). Apesar de sua exclusão a partir dessas discussões, aqueles na rede pública de ensino que se identificam como transexuais ou de gênero não conformes tendem a enfrentar níveis mais elevados de assédio e abuso de seus pares, e em algumas instâncias, de educadores.

Em 2020, 175 mulheres trans foram assassinadas no Brasil. O número representa um aumento de $41 \%$ em relação ao ano anterior, quando 124 pessoas trans foram mortas. O dado é apresentado no dossiê da Associação Nacional de Travestis e Transexuais (Antra), lançado nesta sexta-feira (29), Dia Nacional da Visibilidade Trans. O índice do ano passado está $43,5 \%$ acima da média de assassinatos em números absolutos desde 2008 , 


\section{PRÁTICAS EDUCATIVAS, MEMÓRIAS E ORALIDADES}

Rev.Pemo - Revista do PEMO

quando o monitoramento foi iniciado. Houve um aumento de $201 \%$ dos crimes nesse período.

Isso é explicado por Serano (2009) quando ela insiste que "a busca incessante para descobrir a causa da transexualidade visa manter identidades de gênero transexuais em um estado perpetuamente questionável, garantindo assim que as identidades de gênero cissexuais continuam a ser inquestionáveis "(p. 188). Como resultado, o indivíduo trans sensacionalizado e perpetuamente questionado continua a ser percebido e apresentada como uma anomalia no contexto social. Portanto, é importante que a objetivação de indivíduos trans é desconstruída e alterada a fim de promover uma compreensão de gênero em termos de espectro ou continuum, em oposição a um sistema binário dicotômico, ordenado e duplo.

A criação e implementação de políticas escolares geram o potencial de informar administradores, educadores e, posteriormente, alunos sobre o dinamismo de gênero e que divergir de um sistema cisgênero não exige um rótulo de desvio ((MATTOS, et al., 2016).

Consequentemente, este estudo foi realizado para gerar conhecimento sobre essas políticas e para investigar seus efeitos, especificamente, se elas foram eficazes na criação de um ambiente estimulante para todos os alunos, e não apenas para aqueles que se enquadram perfeitamente no binário de gênero

O Departamento de Educação está empenhado em fornecer ambientes de aprendizagem seguros e de apoio que respeitem e valorizem a diversidade e sejam livres de violência, discriminação, assédio e difamação. O ambiente de apoio que as escolas oferecem pode ter um impacto duradouro nos resultados educacionais e ao longo da vida para os alunos (OLIVEIRA, 2010).

A maioria das pessoas expressa o gênero que corresponde ao seu sexo biológico. Existem algumas pessoas cuja identidade ou expressão de gênero é diferente daquela tradicionalmente associada ao sexo atribuído no nascimento (FERREIRA; NOGUEIRA, 2015a).

Rev.Pemo, Fortaleza, v. 3, n. 3, e335484, 2021

DOI: https://doi.org/10.47149/pemo.v3i3.5484

https://revistas.uece.br/index.php/revpemo

ISSN: 2675-519X

(c) (i) Esta obra está licenciada com uma Licença Creative Commons

Atribuição 4.0 Internacional. 


\section{PRÁTICAS EDUCATIVAS, MEMÓRIAS E ORALIDADES}

Rev.Pemo - Revista do PEMO

Por sua vez, muitos alunos trans - especialmente aqueles que eram considerados trans no ensino médio - podem começar a faculdade com um histórico de vitimização. A faculdade tem a capacidade de reforçar o tratamento transfóbico e de gênero que muitos alunos já experimentaram na escola e na sociedade levando a resultados acadêmicos e psicossociais fracos; ou, para apoiar e capacitar esses alunos potencializando o sucesso acadêmico e pessoal. Para os alunos que não eram trans no ensino médio, a faculdade pode desempenhar um papel importante na facilitação da exploração da identidade de gênero - por exemplo, fornecendo os apoios e recursos necessários para permitir que os alunos naveguem nesse processo enquanto permanecem na faculdade (OLIVEIRA, 2010).

Faculdades e universidades reforçam o gênero social em práticas, políticas e normas). Os alunos trans que procuram expressar suas identidades de gênero encontram pressões para se conformar às normas de gênero socialmente construídas em termos de aparência, vestimenta e pronomes, o que afeta todos os alunos trans, mas especialmente os alunos não binários (BORGES; MEYER, 2008).

Os alunos não binários podem ter dificuldade em se apresentar de maneiras que estejam em consonância com sua identidade de gênero (por exemplo, usando pronomes diferentes de "ela / ela / ela" ou "ele / ele / ela"), visto que enfrentam um escrutínio específico por não procurarem se conformar para ou ser visto como "qualquer" gênero (SOUSA,NASCIMENTO, 2018).

Cisnormatividade e gênero são evidentes em vários domínios dentro do microssistema de ensino superior, de estruturas físicas a registros oficiais a políticas, currículos e práticas de sala de aula e, com o tempo, podem criar estresse crônico para minorias de gênero navegando ativamente por sua identidade dentro tais estruturas restritivas e potencialmente alienantes (COSTA; SILVA; SOUZA, 2019).

É oportuno e pertinente, especialmente considerando que a necessidade de abordar a justiça de gênero no sistema educacional, e especificamente a transfobia, foi identificada como uma questão de direitos humanos significativa, que requer intervenção urgente de acordo com as palavras de Souza e Nascimento (2018).

Rev.Pemo, Fortaleza, v. 3, n. 3, e335484, 2021

DOI: https://doi.org/10.47149/pemo.v3i3.5484

https://revistas.uece.br/index.php/revpemo

ISSN: 2675-519X

(c) (i) Esta obra está licenciada com uma Licença Creative Commons

Atribuição 4.0 Internacional. 


\section{PRÁTICAS EDUCATIVAS, MEMÓRIAS E ORALIDADES}

Rev.Pemo - Revista do PEMO

Portanto, é importante investigar pesquisas educacionais específicas para trans, contextos e práticas de políticas, com o objetivo de gerar conhecimento sobre como as experiências de jovens trans, não-conformidades de gênero e expressão criativa de gênero estão sendo abordadas no sistema educacional.

Além disso, embora haja evidências de políticas de educação trans específicas, existem poucas análises detalhadas ou extensas, de tais políticas, e pesquisas limitadas que investigaram os efeitos dessas políticas, ou que abordaram práticas pedagógicas transafirmativas e expansivas de gênero em a sala de aula (OLIVEIRA, 2010).

Compartilhar essas ruminações sobre as implicações epistemológicas e éticas da necessidade de envolvimento com os estudos sobre transgêneros como uma base para pensar e repensar os termos da análise, pesquisa e prática de políticas públicas em instituições educacionais que estão comprometidas em promover entendimentos transgêneros informados e amplos de gênero da incorporação como eles são refletidos nos documentos incluídos como parte desta edição especial (SILVA et al., 2020)

No que diz respeito às políticas públicas como textos, é importante compreender que as políticas são "representações que são codificados de maneiras complexas (por meio de lutas, compromissos, público autorizado interpretações e reinterpretações) e decodificadas de maneiras complexas (por meio das interpretações dos atores e significados em relação à sua história, experiências, habilidades, recursos e contexto

As escolas, não importa o quanto elas desejem sugerir de forma diferente, estão repletas de opressão de categoria de gênero e opressão de transgressão de gênero. Para superar isso, é imperativo que as políticas direcionem um meio pelo qual essas formas de opressão possam ser totalmente desligados do sistema de ensino. Usando a matriz de opressão de gênero, esta pesquisa irá identificar onde as políticas escolhidas eliminam ou continuam a reforçar o privilégio no contexto de direitos humanos e as políticas afirmativas para travestis e transexuais no ensino superior.

\section{Considerações finais}

Rev.Pemo, Fortaleza, v. 3, n. 3, e335484, 2021

DOI: https://doi.org/10.47149/pemo.v3i3.5484

https://revistas.uece.br/index.php/revpemo

ISSN: 2675-519X

(c) (i) Esta obra está licenciada com uma Licença Creative Commons

Atribuição 4.0 Internacional. 


\section{PRÁTICAS EDUCATIVAS, MEMÓRIAS E ORALIDADES}

Rev.Pemo - Revista do PEMO

A partir do que foi exposto ao longo desse trabalho sobre o desafio de saber lidar com a heterogeneidade no universo escolar, na perspectiva da diversidade sexual levando em consideração, que na prática, o cotidiano escolar é determinado pela homogeneidade, foi possível afirmar que esse estudo, após leituras, investigações e inferências sobre o assunto, aponta caminhos que devem ser levados em consideração com a finalidade de compartilhar explicações que possam ser uteis ao universo escolar brasileiro no processo de desconstrução da homogeneidade.

Dessa maneira, percebe-se que a educação brasileira é homogênea por várias razões que se constituem em desafios para a mesma: se pauta num paradigma educacional ainda movido por interesses historicamente elitista e conservador; os professores têm posturas preconceituosas pautadas em ideias cristalizadas cujo o papel da escola é desconstruí-las, com base na ciência; os mecanismos ainda utilizados pelo sistema de ensino no Brasil, como currículos, livros didáticos, datas comemorativas, cartazes e discursos escolares, são eivados da ideologia das classes dominantes, negando as diferenças e reforçando aquilo que lhes interessa; a escola continua sendo seguidora de modelos de Estado e governos que representam os interesses capitalistas neoliberais que se sobrepõem aos interesses das classes populares ou menos favorecidas, ao suprimir verbas fundamentais para políticas públicas comprometidas com a qualidade e desenvolvimento da educação e da sociedade, forte influenciadas religiões neopentecostais fundamentalistas, influência política conservadora das bancadas evangélicas e católicas no Congresso Nacional, etc.

A diversidade é geralmente entendida como abrangendo raça, etnia, classe, gênero, sexualidade, idade e crenças políticas e religiosas. E enquanto no passado ele se concentrou no fortalecimento da tolerância intercultural, novas ideias sobre diversidade e inclusão se desenvolveram, mudando o foco para enriquecer o aprendizado e a experiência humana, a chamada "unidade na diversidade".

Quando se trata de educação, a "unidade na diversidade" na sala de aula não parece mais uma ideia exagerada para qualquer professor de mente global. Isso pode ser conseguido com a tecnologia que conecta os alunos com conhecimentos e culturas

Rev.Pemo, Fortaleza, v. 3, n. 3, e335484, 2021

DOI: https://doi.org/10.47149/pemo.v3i3.5484

https://revistas.uece.br/index.php/revpemo

ISSN: 2675-519X

(c) (i) Esta obra está licenciada com uma Licença Creative Commons

Atribuição 4.0 Internacional. 


\section{PRÁTICAS EDUCATIVAS, MEMÓRIAS E ORALIDADES}

Rev.Pemo - Revista do PEMO

estrangeiras ou com um corpo discente internacional para tornar o ambiente de aprendizado multicultural e diversificado.

Além disso, a realidade retratada sugere que a via judicial pode ser a alternativa menos difícil para o desenvolvimento do respeito aos direitos humanos relacionados à diversidade sexual, dada a ação legislativa pode tender a reforçar elementos proibitivos em países onde a hegemonia cultural e religiosa pode ser expressa por meio de ação legislativa. Nesses países, os tribunais podem fornecer a oportunidade para uma discussão mais aberta.

O próximo passo é apontar possibilidades de superação das situações proibitivas e de negação de direitos associados à diversidade sexual, principalmente na educação.

\section{Referências}

AZEVEDO, Janete M. L. A educação como política pública. Campinas: Autores Associados, 1997.

BORGES, Z. N.; MEYER, D. E. Limites e possibilidades de uma ação educativa na redução da vulnerabilidade à violência e à homofobia. Avaliação e Políticas Públicas em Educação, v.16, n.58, p.59-76, 2008.

COSTA, A. da M.; SILVA, F. C. da; SOUZA, D da S. Parceria entre escola e família na formação integral da criança. Práticas Educativas, Memórias e Oralidades, v. 1, n. 1, 1 jan. 2019. Disponível em: <https://revistas.uece.br/index.php/revpemo/article/view/3476> Acesso em: 25 de abril de 2021.

DANILIAUSKAS, Marcelo. Relações de gênero, diversidade sexual e políticas públicas de educação: uma análise do Programa Brasil Sem Homofobia. 2011. Dissertação (Mestrado em educação) - Faculdade de Educação da Universidade de São Paulo, São Paulo, 2011.

FERRARI, Anderson. Revisando o passado e construindo o presente: o movimento gay como espaço educativo. Revista Brasileira de Educação, Campinas, Autores Associados, n. 25, jan./fev./mar./abr., p. 105-115, 2004.

FERREIRA, L. A. M.; NOGUEIRA, F. M. de B. Impactos das Políticas Educacionais no cotidiano das Escolas Públicas Plano Nacional de Educação, Revista @rquivo Brasileiro de Educação, Belo Horizonte, v.3, n.5, p.23-28, 2015. Disponível em: 


\section{PRÁTICAS EDUCATIVAS, MEMÓRIAS E ORALIDADES}

Rev.Pemo - Revista do PEMO

<http://pne.mec.gov.br/images/pdf/Noticias/impactos_politicas_educacionais_cotidiano_e scolas_publica_PNE.pdf > Acesso em: 25 de abril de 2021 .

FONSECA, K. A. Análise de adequações curriculares no ensino fundamental: subsídios para programas de pesquisa colaborativa na formação de professores. 2011 . 126f. Dissertação (Mestrado em Psicologia do Desenvolvimento e Aprendizagem) Universidade Estadual Paulista, Faculdade de Ciências, Bauru, 2011

FACCHINI, Regina. Sopa de letrinhas?: movimento homossexual e produção de identidades coletivas nos anos 90. Rio de Janeiro: Garamond, 2005.

GIL, Antônio Carlos. Métodos e técnicas de pesquisa social. 6. ed. São Paulo: Atlas, 2010.

LIRA, Andréia Maria Silva. O tema transversal "orientação sexual" nos PCN e atitude dos professores: convergentes ou divergentes? 2009. Dissertação (Mestrado) Universidade Federal Rural de Pernambuco, 2009.

LOURO, Guacira Lopes Gênero, sexualidade e educação. Guacira Lopes Louro Petrópolis, RJ Uma perspectiva pós-estruturalista: Vozes, 1997.

MATTOS, A.; FIAMENGHI-JÚNIOR, G. A.; CARVALHO, S.; BLASCOVI-ASSIS, S. M. Inclusão social de crianças com deficiências múltiplas no cotidiano escolar. Educação \& Formação, v. 1, n. 2, p. 184-207, 2016. Disponível em:

https://revistas.uece.br/index.php/redufor/article/view/108> Acesso em: 25 de abril de 2021.

MICHALISZYN, Mario Sergio. Educação e Diversidade. Curitiba: IBPEX, 2011.

OLIVEIRA, A. F. Políticas públicas educacionais: conceito e contextualização numa perspectiva didática. In: OLIVEIRA, A. F. Fronteiras da educação: tecnologias e políticas. Goiânia: EdPUC, 2010.

ROSSI, Alexandre. Avanços e limites no combate à homofobia: uma análise do processo de implementação do Programa Brasil sem Homofobia. 2010. Dissertação (Mestrado) - Universidade Federal do Rio Grande do Sul, Porto Alegre, 2010.

SILVA, J. L.; SILVA, L.; PARENTES, M.; SILVA, R. Um olhar sobre a educação inclusiva no PNE 2014-2024: desafios e perspectivas. Práticas Educativas, Memórias e

Oralidades, v. 2, n. 1, 2020. Disponível em:

<https://revistas.uece.br/index.php/revpemo/article/view/3514> Acesso em: 25 de abril de 2021. 


\section{PRÁTICAS EDUCATIVAS, MEMÓRIAS E ORALIDADES}

Rev.Pemo - Revista do PEMO

SOUSA, N. M.; NASCIMENTO, D. A inclusão escolar e o aluno com síndrome de Down: as adaptações curriculares e a avaliação da aprendizagem. Educação \& Formação, Fortaleza, v. 3, n. 3, p. 121-140, 2018. Disponível em: $<$ https://revistas.uece.br/index.php/redufor/article/view/859> Acesso em: 25 de abril de 2021.

VIANNA, Claudia. Estudos de gênero, sexualidade e políticas de educação: das ações coletivas aos planos e programas federais. 2011. Tese (Livre Docência) - Faculdade de Educação, Universidade de São Paulo, 2011.

VIANNA, Cláudia. Introdução do gênero e da sexualidade nas políticas públicas de educação: exame de sua concretização em algumas escolas públicas do estado de São Paulo. São Paulo: [s. n.], 2012. Projeto Produtividade em Pesquisa (CNPq/PQ), 20102012.

' Thiago Luiz Sartori, Universidade Anhanguera, UniABC, Santo André, SP ORCID: https://orcid.org/0000-0002-8295-0661 Universidade Anhanguera

Mestre em Educação. Professor Adjunto da Universidade Anhanguera. Palestrante do Departamento de Cultura e Eventos da OAB/SP.

Contribuição de autoria: desenvolveu todo o estudo.

Lattes: http://lattes.cnpq.br/6868880323818692 .

E-mail: tlsartori@hotmail.com

Editora responsável: Cristine Brandenburg Especialista ad hoc: Caroline Fockink Ritt

\section{Como citar este artigo (ABNT):}

SARTORI, Thiago Luiz. Políticas Públicas, Educação para os Direitos Humanos e Diversidade Sexual. Práticas Educativas, Memórias e Oralidades -Rev. Pemo, Fortaleza, v. 3, n. 3, e335484, 2021. Disponível em: https://doi.org/10.47149/pemo.v3i3.5484 